J. Lake Sci. (湖泊科学) , 2019, 31(4): 1169-1181

DOI 10. 18307/2019. 0403

(c) 2019 by Journal of Lake Sciences

\title{
青藏高原东南部巴松措现代沉积过程及其对气候变化的响应”
}

\author{
马学志 ${ }^{1}$, 王永波 ${ }^{* *}$, 赵辰辰 $^{1}$, 倪振宇 ${ }^{1,2,3}$ \\ (1: 首都师范大学资源环境与旅游学院, 北京 100048$)$ \\ (2: 中国科学院南京地理与湖泊研究所,南京 210008) \\ (3: 中国科学院大学, 北京 100049)
}

\begin{abstract}
摘 要: 湖泊沉积物是记录气候演化信息的重要载体之一,在探讨过去气候变化过程研究中发挥重要作用. 然而,沉积物 中的许多代用指标对气候的指示意义存在多解性,不同指标所反映的环境信息相互之间有时会存在矛盾. 为了能够更准 确地解读湖泊沉积物中指标所记录的环境变化信息, 开展现代湖泊沉积物指标与环境之间的关系研究, 深人探讨各指标 对环境变化的响应机制尤为关键. 本文选取青藏高原东南部巴松措湖泊表层沉积物作为研究对象, 利用 ${ }^{210} \mathrm{~Pb}$ 与 ${ }^{137} \mathrm{Cs}$ 比 活度检测结果建立年代序列, 对沉积物中粒度、磁化率、有机质含量等指标进行分析, 揭示巴松措现代沉积过程. 结合沉 积物粒度端元组分分析结果, 并将不同指标变化与林芝气象站所记录的数据资料进行对比,得出以下主要结论: 该地区 沉积物来源主要包括径流搬运的冰川碎屑物质和来自青藏高原南部、西南部上空悬浮于大气中的风成物质两部分; 其 中, 通过风力搬运的物质输人主要集中在冬半年, 受季节性风向及风速变化影响明显; 径流受到冰雪融水与夏季降水的 补给, 因此通过径流搬运的物质输人量受到温度与降水综合影响; 湖泊中磁性矿物碎屑的产生和输人主要受区域降水量 影响的流域侵蚀速率变化控制, 该湖泊沉积物磁化率波动可以有效的指示该地区降水量变化; 沉积物中总有机碳含量和 总氮含量变化主要反映湖泊自身初级生产力的变化,对区域温度变化的响应显著.
\end{abstract}

关键词: 青藏高原;巴松措;湖泊沉积物;气候变化;现代过程

\section{Modern sedimentary process of Lake Basomtso in the southeastern Tibetan Plateau and its response to climate change}

\author{
MA Xuezhi ${ }^{1}$, WANG Yongbo ${ }^{1 * *}$, ZHAO Chenchen ${ }^{1}$ \& NI Zhenyu ${ }^{1,2,3}$ \\ (1: College of Resource Environment and Tourism, Capital Normal University, Beijing 100048, P.R.China) \\ (2: Nanjing Institute of Geography and Limnology, Chinese Academy of Sciences, Nanjing 210008, P.R. China) \\ (3: University of Chinese Academy of Sciences, Beijing 100049, P.R.China)
}

Abstract: Lacustrine sediment has been regarded as one of the most important archives for inferring information about past climate fluctuations, which presented significant palaeoclimate sequences at different time scales. Various proxies have been investigated to acquire signals of climate changes, which, however, does not always lead to consistent inferences. In order to acquire the information of reliable climate changes from lake sediments, we now intend to investigate the relationship between sedimentary proxies and environment parameters especially the climate changes, to explore how the proxies respond to environment change. Thus, we chose Lake Basomtso from the southeastern Tibetan Plateau as our study area considering the high sedimentation rate and rare human activities. Combined with the chronology based on measurements of ${ }^{210} \mathrm{~Pb}$ and ${ }^{137} \mathrm{Cs}$, grain size, magnetic susceptibility and organic matter content of the modern sediments from both sediment cores and traps were analyzed. The results were subsequently compared with modern meteorological data from Nyingchi Station. The sediment mainly consists of two parts : the aeolian transported materials during the winter time from the south and southwest of the Tibetan Plateau, which showed significant consistence with the regional wind speed; and the fluvial transported materials that influenced by the temperature (melting effect) and precipitation together. The fluctuation of magnetic susceptibility of lake sediment of Lake Basomtso mainly reflects the input of magnetic mineral, which is

* 国家自然科学基金项目 $(41877282,41502325)$ 和首都师范大学高层次人才教学科研支持费 $(011185516000)$ 联合 资助. 2018-11-22 收稿;2018-11-30 收修改稿. 马学志 (1993 ), 男, 硕士研究生; E-mail: 476846708@ qq.com.

** 通信作者;E-mail: yongbowang@ cnu.edu.cn. 
closely affected by the precipitation related erosion rate. Finally, the variation of total organic carbon, total nitrogen content generally showed a gradual increasing trend of lake primary productivity, which responds closely to the changes of temperature, especially the global warming process.

Keywords: Tibetan Plateau; Lake Basomtso; lacustrine sediment; climate change; modern sedimentation process

湖泊沉积物作为陆地上广泛分布的古气候记录载体, 其沉积过程相对连续且稳定, 在获取千年、百年以 及十年时间尺度上的气候演化序列研究中发挥着重要作用 ${ }^{[1-2]}$. 自 $1980 \mathrm{~s}$ 以来, 我国便开始了第四纪湖泊沉 积物记录的系统研究, 取得了丰硕的成果, 为重建过去气候环境演化历史提供了丰富的资料 ${ }^{[3-5]}$.

在过去环境变化过程的重建当中, 从湖泊沉积物中提取的不同气候代用指标均具有重要指示意义,如 粒度、磁化率、有机质含量、元素组成、矿物组成以及烧失量等, 得到广泛应用 ${ }^{[4-5]}$. 例如, 沉积物粒度组分的 变化一定程度上可以反映沉积环境及搬运动力条件的强弱, 进而揭示相应的水动力变化 ${ }^{[6]}$ 、风力搬运过程 变化 ${ }^{[7]}$ 以及其他因素对沉积过程的影响 (如冰川的进退 ${ }^{[8]}$ ). 磁化率的高低能够反映湖泊沉积物中磁性矿物 组成及变化情况, 进而揭示相对应的流域内侵蚀、风化作用的强弱, 以及背后的潜在影响因素 (如人类活 动 $^{[9]}$ ). 沉积物中有机碳氮含量能够反映湖泊水体以及流域内生产力变化, 而有机碳氮比值变化可进一步判 断沉积物中有机质来源, 并指示气候环境变化在其中的影响 ${ }^{[10]}$. 然而, 湖泊沉积物中的许多指标具有多解 性, 同一指标在不同情况下所反映的环境变化信息存在不一致性甚至是矛盾的. 例如, 沉积物中总有机碳含 量 (TOC) 所指示的湖泊初级生产力变化可能主要受温度 ${ }^{[11]}$ 、降水 ${ }^{[12]}$ 或两者共同影响, 如泸沽湖 ${ }^{[13]}$; 除此之 外,湖泊水位、水深等因素同样可以在一定程度上影响沉积物中有机碳含量变化 ${ }^{[14-15]}$. 沉积物粒度变粗可能 是由于湖泊水位下降、面积收缩导致采样点位置更靠近湖滨, 水动力条件增强所造成, 反映水位较低的相对 干旱气候环境 ${ }^{[16]}$; 另一方面, 沉积物中粗颗粒组分含量增加也可以解释为流域内水动力条件加强, 指示降水 量较大的相对湿润气候 ${ }^{[17]}$. 因此, 为了更准确地利用这些指标进行气候变化重建, 开展现代湖泊沉积过程 的系统研究, 深刻理解沉积物中各指标对现代气候变化因素的响应过程尤为重要.

随着过去气候变化研究的广泛开展, 现代沉积过程和沉积学指标的环境响应机制研究逐步得到研究者 的关注, 如巴丹吉林沙漠中的诸多湖泊 ${ }^{[14-15]}$ 、星云湖 ${ }^{[18]}$ 、固城湖 ${ }^{[19]}$ 以及鄱阳湖 ${ }^{[20]}$ 等, 然而这其中部分研究 多以我国东部地区湖泊为研究对象, 受人类活动影响严重, 其现代沉积过程多受到干扰. 相比之下, 青藏高 原地区受人类活动影响较少, 且由于海拔高、积雪面积大等特殊的下垫面性质, 在亚洲夏季风的影响下对气 候变化非常敏感, 高原上广泛分布的湖泊成为研究气候变化过程的理想选择 ${ }^{[21-23]}$. 因此, 对该地区湖泊现代 沉积过程的研究可以有效地揭示不同指标对现代气候变化的响应过程.

为了深人理解湖泊沉积物各指标对环境变化的响应过程, 探讨气候代用指标的环境指示意义, 本文选 择青藏高原东南部的湖泊巴松措作为研究对象. 已有研究结果表明, 巴松措沉积速率可达 $0.5 \mathrm{~cm} / \mathrm{a}^{[24]}$, 为开 展高分辨率的现代沉积过程研究提供了理想材料. 因此, 我们拟通过对巴松措沉积物捕获器中收集的现代 沉积物以及沉积物短岩芯样品进行粒度、磁化率、有机质含量等实验分析, 结合巴松措所在地区的现代器测 气象资料,探讨巴松措现代沉积过程以及各沉积学指标对气候的响应机制.

\section{1 研究区域概况}

巴松措 $\left(30^{\circ} 0^{\prime} 1^{\prime \prime} \sim 30^{\circ} 2^{\prime} 53^{\prime \prime} \mathrm{N}, 93^{\circ} 53^{\prime} 37^{\prime \prime} \sim 94^{\circ} 1^{\prime} 48^{\prime \prime} \mathrm{E}\right)$ 位于青藏高原东南部, 处于念青唐古拉山与喜马拉 雅山交汇处, 湖面海拔约 $3480 \mathrm{~m}$ a.s.l. (图 1a). 湖水矿化度为 $0.12 \mathrm{~g} / \mathrm{L}$, 最大深度约为 $120 \mathrm{~m}$, 湖水总面积 26 $\mathrm{km}^{2}$, 流域面积约为 $1290 \mathrm{~km}^{2}$ (图 1b). 巴松措湖泊呈狭长的条状, 两侧陡坡中间平缓, 分为东、西两个湖盆, 是以冰川补给为主的开放性淡水湖 (图 1c). 巴松措所在的林芝地区属于典型的高原气候, 根据位于巴松措 东南 $65 \mathrm{~km}$ 处林芝气象站 1960 年以来记录显示, 该地区 7 月和 1 月平均气温分别约为 $15.9^{\circ} \mathrm{C}$ 和 $0.9^{\circ} \mathrm{C}$, 年均

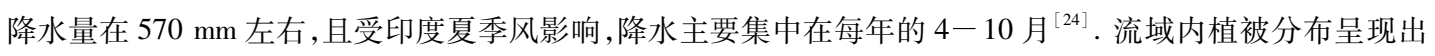
明显的垂直地带性, 自下而上依次为云冷杉针叶林 (急尖长苞冷杉林 Abies georgei var. smithii forest、林芝云杉 林 Picea likiangensis var. lintziensis forest), 亚高山常绿针叶灌丛(香柏、高山柏、滇藏方枝柏灌丛 Sabina pingii var. wilsonii, S. squamata, S. wallichiana scrub) 混高寒草甸 (小蒿草高寒草甸 Kobresia pygmaea alpine mead- 
ow), 以及高山稀疏植被 (水母雪莲、风毛菊稀疏植被 Saussurea medusa, Saussurea spp. Sparse vegetation) ${ }^{[25]}$.
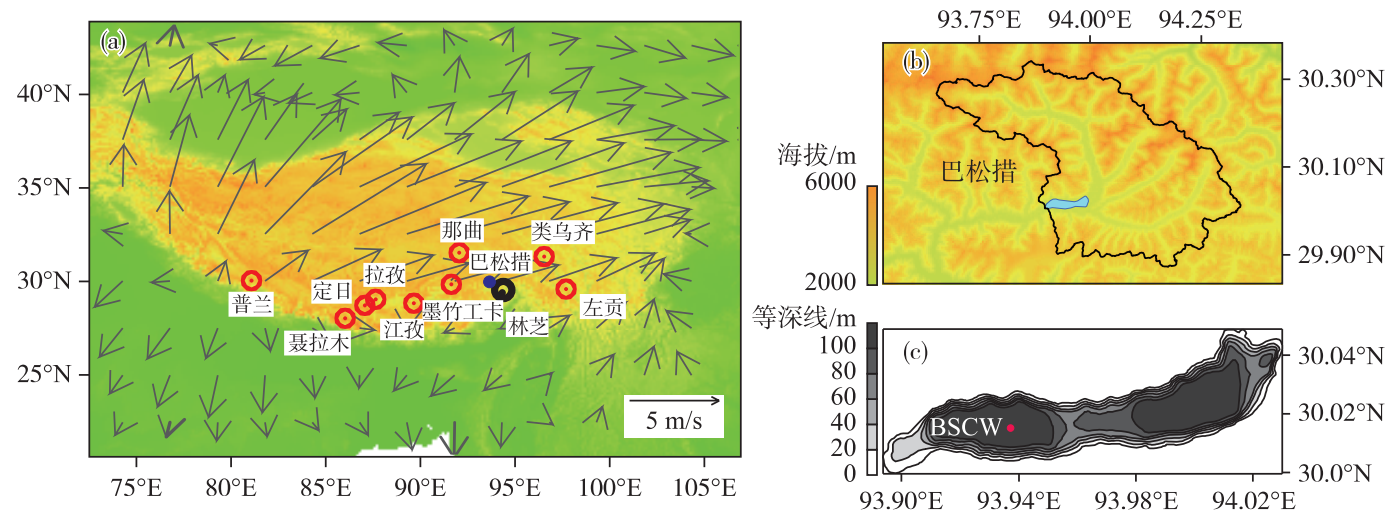

图 1 青藏高原及其附近地区冬季风场图及西藏地区部分气象站点分布 ${ }^{[26]}$ (a),

巴松措区域位置及其流域分布 (b) 及湖泊等深线图 (c)

Fig.1 Winter wind field of the Tibet Plateau and its vicinity and the locations of meteorological stations in Tibet ${ }^{[26]}(a)$, the location and the watershed of Lake Basomtso basin (b) and bathymetry contour (c)

\section{2 样品采集及方法}

\section{1 样品采集}

于 2016 年 5 月,利用重力采样器在巴松措西部湖盆采样点 $\mathrm{BSCW}\left(30^{\circ} 01^{\prime} \mathrm{N}, 93^{\circ} 56^{\prime} \mathrm{E}\right)$ 采集到长度为 $44.5 \mathrm{~cm}$ 的沉积物岩芯 BSCW-1 (图 1c). 岩芯运回实验室后, 按 $0.5 \mathrm{~cm}$ 间隔分样,共分得 89 份样品. 同时, 在 采样点 (图 1c) 附近放置了自制沉积物捕获器用以收集湖泊现代沉积物. 捕获器由一系列绑定在绳子上的 $50 \mathrm{ml}$ 离心管组成, 间隔 $2 \mathrm{~m}$, 绳子底端被重物固定于水底, 绳子顶端接近水面处绑有若干浮球保证其直立于 水中. 两组捕获器分别于 2016 年 5 月和 11 月放置并于 2016 年 11 月和 2017 年 5 月回收, 用以收集夏季和 冬季的现代沉积物样品.

\section{2 年代测试}

冷冻干燥后的 BSCW-1 样品, 以 $1 \mathrm{~cm}$ 间隔进行 ${ }^{210} \mathrm{~Pb}$ 和 ${ }^{137} \mathrm{Cs}$ 放射性比活度测量, 该测试在中国科学院南 京地理与湖泊研究所湖泊与环境国家重点实验室, 利用 ORTEC GWL 井型高纯锗 ( HPGe) $\gamma$ 能谱仪完成. 钻 孔年代学的建立采用 ${ }^{210} \mathrm{~Pb}$ 复合模式, 根据 ${ }^{210} \mathrm{~Pb}$ 比活度沉积之后开始衰减并随沉积年龄增长而降低的规律 建立 CRS 模式年底序列, 所得结果再利用 ${ }^{137} \mathrm{Cs}$ 测年时标 (1954 年出现, 1963 年达到峰值) 进行校正, 建立钻 孔年代序列 ${ }^{[27]}$.

\section{3 沉积学指标分析}

对岩芯样品和捕获器收集的现代样品进行粒度分析. 过程如下: 取 $0.5 \mathrm{~g}$ 左右样品置于烧杯中, 加人 10 $\mathrm{ml}$ 浓度为 $10 \%$ 的过氧化氢 $\left(\mathrm{H}_{2} \mathrm{O}_{2}\right)$ 溶液以去除样品中的有机质, 通过水浴加热加速反应; 反应完毕后加人 10 $\mathrm{ml} \mathrm{10 \%}$ 的稀盐酸 ( $\mathrm{HCl}$ ) 溶液以去除样品中的碳酸盐, 待反应完毕后将样品洗至中性; 加人 $10 \mathrm{ml} 10 \%$ 的六偏 磷酸钠 $\left[\left(\mathrm{NaPO}_{3}\right)_{6}\right]$ 溶液作分散剂, 并进行超声波震荡 15 20 min, 随后利用 Malvern Mastersizer 3000 激光粒 度仪进行测量. 为了进一步获取粒度变化信息, 揭示其沉积过程, 对测量后的粒径分布结果进行端元组分分 析 (EMMA,End-Member Modelling Algorithm). 端元组分分析是一种基于主成分分析、因子旋转和非负最小 二乘法等统计学分析方法的分析模式, 能够将粒度分布结果拆分成若干具有地学意义的端元, 以揭示其搬 运及沉积过程, 在湖泊沉积物研究中得到广泛应用 ${ }^{[7]}$. 端元组分分析在 R 3.4.4 程序中利用 EMMAgeo 程序 包完成 ${ }^{[28]}$.

岩芯磁化率测量以 $0.5 \mathrm{~cm}$ 为间距取样, 并装人边长为 $1.5 \mathrm{~cm}$ 的立方体样品盒中, 称重后利用 Bartington MS2 磁化率仪, 使用 SI 模式对样品进行高频和低频磁化率的测量, 同一样品进行 3 次测量, 求得最后平 
均值.

总有机碳( TOC) 、总氮 ( TN) 含量的测量以岩芯样品为分析对象. 利用 $10 \%$ 的 $\mathrm{HCl}$ 溶液除去样品中的碳 酸盐, 用蒸馏水清洗至中性后冷冻干燥并研磨. 样品测试在中国科学院南京地理与湖泊研究所湖泊与环境 国家重点实验室利用 CE440 型元素分析仪完成.

\section{3 结果}

\section{1 测年结果}

沉积物岩芯的 ${ }^{210} \mathrm{~Pb}_{\text {ex }}$ 比活度随深度增加呈现出明显的指数递减规律, 比活度最大值 $375 \mathrm{~Bq} / \mathrm{kg}$ 出现于 近岩芯表层处样品, 此深度之下随深度增加其比活度在波动中递减 (图 2a). 另一方面, 样品中 ${ }^{137} \mathrm{Cs}$ 比活度 呈现出明显的单峰模式, 表层附近的比活度低于 $20 \mathrm{~Bq} / \mathrm{kg}$, 之后随深度增加而逐渐增大, 于 $15.5 \mathrm{~cm}$ 深度位 置达到最大值 $72 \mathrm{~Bq} / \mathrm{kg}$, 之后其比活度随深度增加而骤降, 并最终在 $20.5 \mathrm{~cm}$ 深度以下消失 (图 $2 \mathrm{~b}$ ) ${ }^{137} \mathrm{Cs}$ 作 为一种人工放射性核素, 主要来源于大气核试验及核事故,通过大气扩散沉降至地表, 由于其分布广泛及易 于测量, 在现代湖泊沉积过程研究的年代序列建立中得到广泛应用 ${ }^{[29-30]}$. 研究表明 ${ }^{137} \mathrm{Cs}$ 最早是于 1954 年随 着核试验的进行开始散落,并在 1963 年左右因全球大气核试验进人最集中时期而达到最大散落量 ${ }^{[30]}$. 因 此, 根据 ${ }^{137} \mathrm{Cs}$ 比活度结果确定开始出现比活度的 $20.5 \mathrm{~cm}$ 深度对应的年代为 1954 年, 达到最大蓄积峰的 $15.5 \mathrm{~cm}$ 深度对应年代为 1963 年. ${ }^{137} \mathrm{Cs}$ 比活度确定的 1954 年、1963 年时标与 ${ }^{210} \mathrm{~Pb}_{\mathrm{ex}}$ 比活度恒定补给速率 (CRS) 模式建立的年代序列 (图 2c) 呈现出较好的一致性, 表明钻孔顶部 $30 \mathrm{~cm}$ 岩芯沉积过程较为稳定. 我 们还利用 ${ }^{137} \mathrm{Cs}$ 时标对 ${ }^{210} \mathrm{~Pb}_{\text {ex }}$ 的 CRS 年代序列进行矫正, 建立了钻孔顶部 $30 \mathrm{~cm}$ 沉积物年代模式. 并且通过 对比发现, 矫正后的年代序列与利用巴松措沉积物岩芯纹层建立的年代序列 ${ }^{[24]}$ 结果具有较好的一致性. 钻 孔沉积速率整体比较平稳,岩芯顶部沉积速率略低于 $15.5 \mathrm{~cm}$ 以下部分.
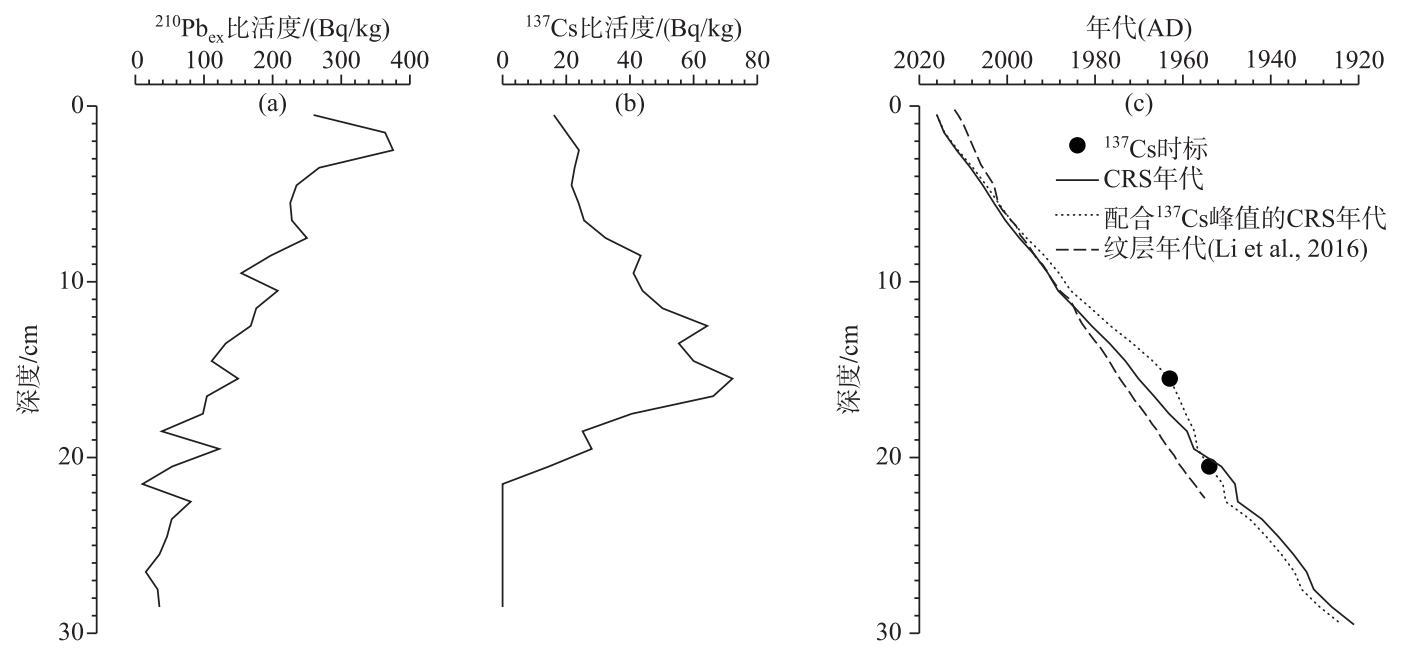

图 2 巴松措沉积物岩芯样品 ${ }^{210} \mathrm{~Pb}_{\mathrm{ex}}(\mathrm{a}) 、{ }^{137} \mathrm{Cs}(\mathrm{b})$ 比活度随深度变化及 $\mathrm{CRS}$ 模式年代序列 $(\mathrm{c})$

Fig. 2 The relationship between the radioactivity detection results of ${ }^{210} \mathrm{~Pb}_{\mathrm{ex}}(\mathrm{a})$ and ${ }^{137} \mathrm{Cs}(\mathrm{b})$, the age-depth relationship based on CRS model (c) of the core sediment in Lake Basomtso

\section{2 粒度结果}

巴松措沉积物岩芯中样品各粒级组分含量随时间的变化如图 3 所示, 样品整体上以粒径小于 $4 \mu \mathrm{m}$ 的 黏土和粒径在 4 16 $\mu \mathrm{m}$ 之间的细粉砂为主, 各占 $40 \%$ 左右. 沉积物岩芯样品中粗颗粒砂组分 ( $>64 \mu \mathrm{m}$ ) 含 量极低,在 $0.5 \%$ 左右波动变化.

捕获器中收集的夏季和冬季现代沉积物粒度组成 (图 4) 与岩芯中样品结果相似, 同样以黏土和细粉砂 为主, 各占沉积物的 $40 \%$ 左右. 另一方面, 巴松措现代沉积物呈现出较为明显的季节性变化, 细粉砂 (4 


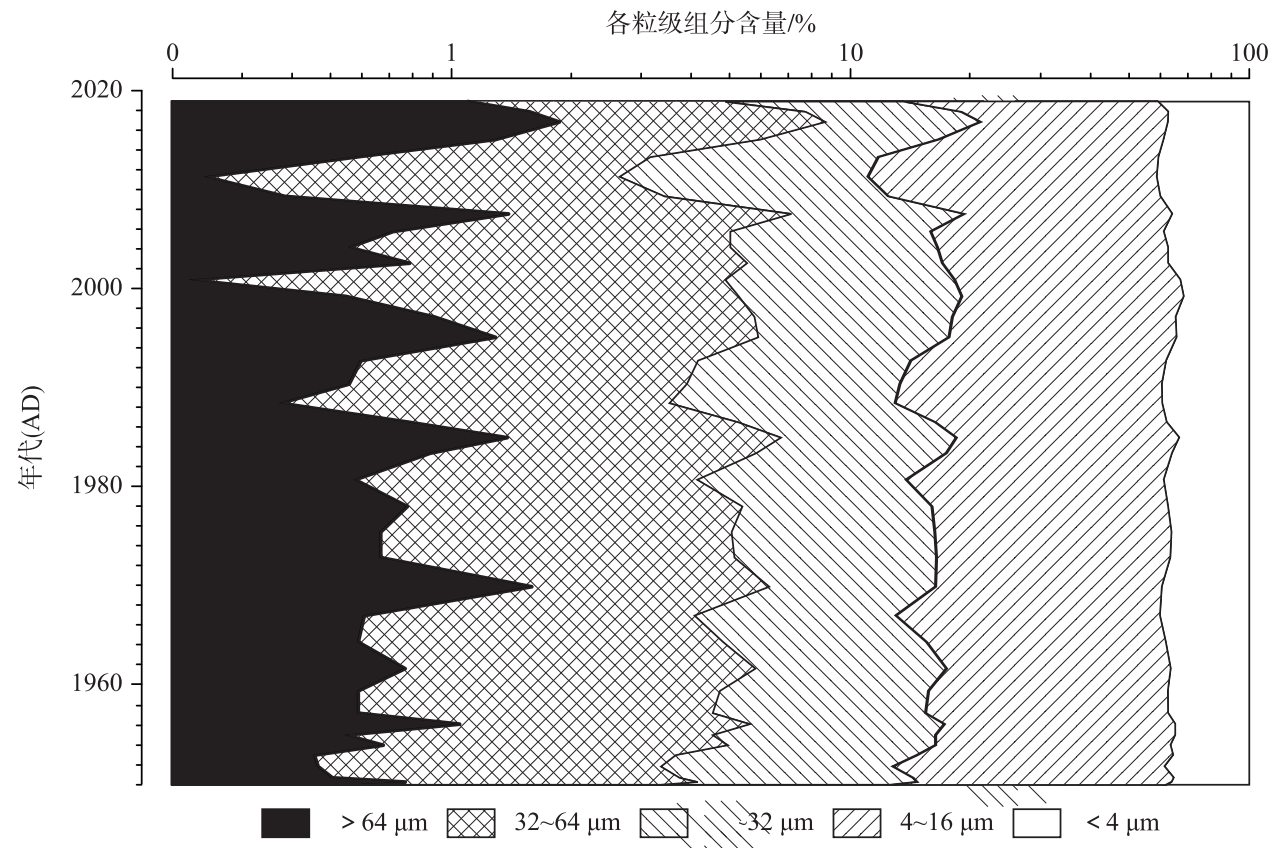

图 3 巴松措沉积物岩芯样品各粒级百分比含量

Fig.3 Variations of grain size compositions of the core sediment in Lake Basomtso

$16 \mu \mathrm{m}$ 组分) 在夏季沉积物中含量明显高于冬季; 而颗粒较粗的中粉砂 ( $16 \sim 32 \mu \mathrm{m}$ 组分)、粗粉砂 ( $32 \sim 64$ $\mu \mathrm{m}$ 组分) 和砂 ( $>64 \mu \mathrm{m}$ 组分) 在冬季沉积物中的含量均高于夏季, 尤其是粒径大于 $64 \mu \mathrm{m}$ 的砂组分, 几乎 只有在冬季的沉积物中被收集到.
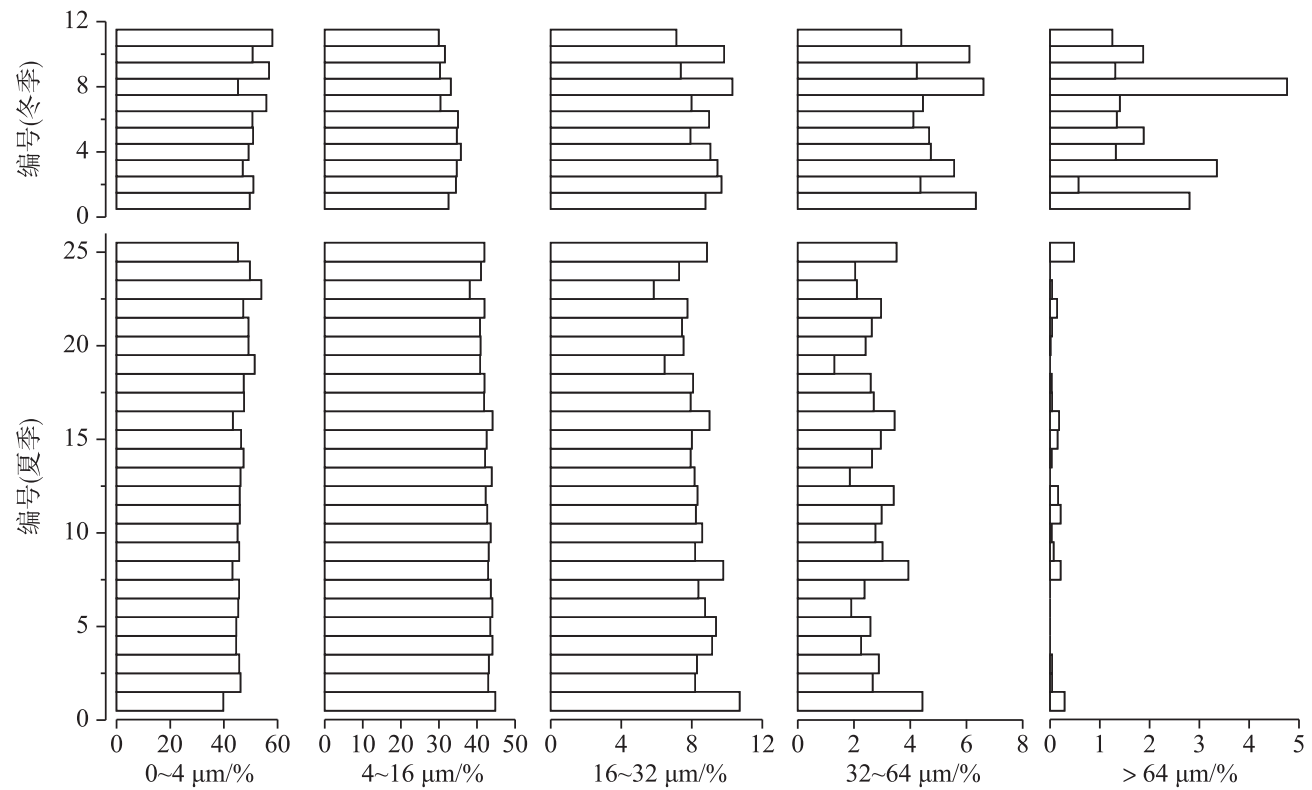

图 4 巴松措沉积物捕获器中样品的粒度分析结果

Fig.4 Grain size compositions of modern trap sediments in Lake Basomtso 
巴松措岩芯和捕获器中沉积物样品的粒度端元组分分析结果表明, 当端元数为 3 的时候可以解释 $81 \%$ 的粒度组成变化 (图 5a), 考虑到端元数的选择需要能够解释尽可能多的组分和尽量少的端元数 ${ }^{[31]}$, 因此选 取端元个数为 3 进行分析 (图 5b). 在获取到的 3 个端元组分中, EM1 组分粒径分布呈现双峰模式, 分别在 $0.8 \mu \mathrm{m}$ 和 $11 \mu \mathrm{m}$ 处出现峰值. EM2 组分以细颗粒物质为主, 集中分布在 $0.2 \sim 10 \mu \mathrm{m}$ 之间, 并分别在 $0.7 \mu \mathrm{m}$ 和 $3 \mu \mathrm{m}$ 左右出现峰值, 仅有小部分颗粒分布于粒径 10 200 $\mu \mathrm{m}$ 之间. EM3 组分呈现明显的单峰模式, 在 0.4 100 $\mu \mathrm{m}$ 之间呈正态分布, 并在 $5 \mu \mathrm{m}$ 左右出现最大值. 各端元组分在样品中的分布也存在明显差异(图 $5 c$ ), EM1 组分主要出现在岩芯和现代冬季沉积物中, 其组成在 $20 \% \sim 60 \%$ 间波动; EM2 组分仅在捕获器中 收集的现代沉积物中出现, 冬季沉积物中组成( $60 \% \sim 80 \%)$ 明显高于夏季沉积物 ( $20 \% \sim 40 \%)$, 并且呈现出 随湖水深度降低而增加的趋势; EM3 组分则出现在岩芯和现代夏季沉积物中, 其组成多数均在 50\% 以上甚 至可达 $80 \%$, 冬季现代沉积物中含量极低.
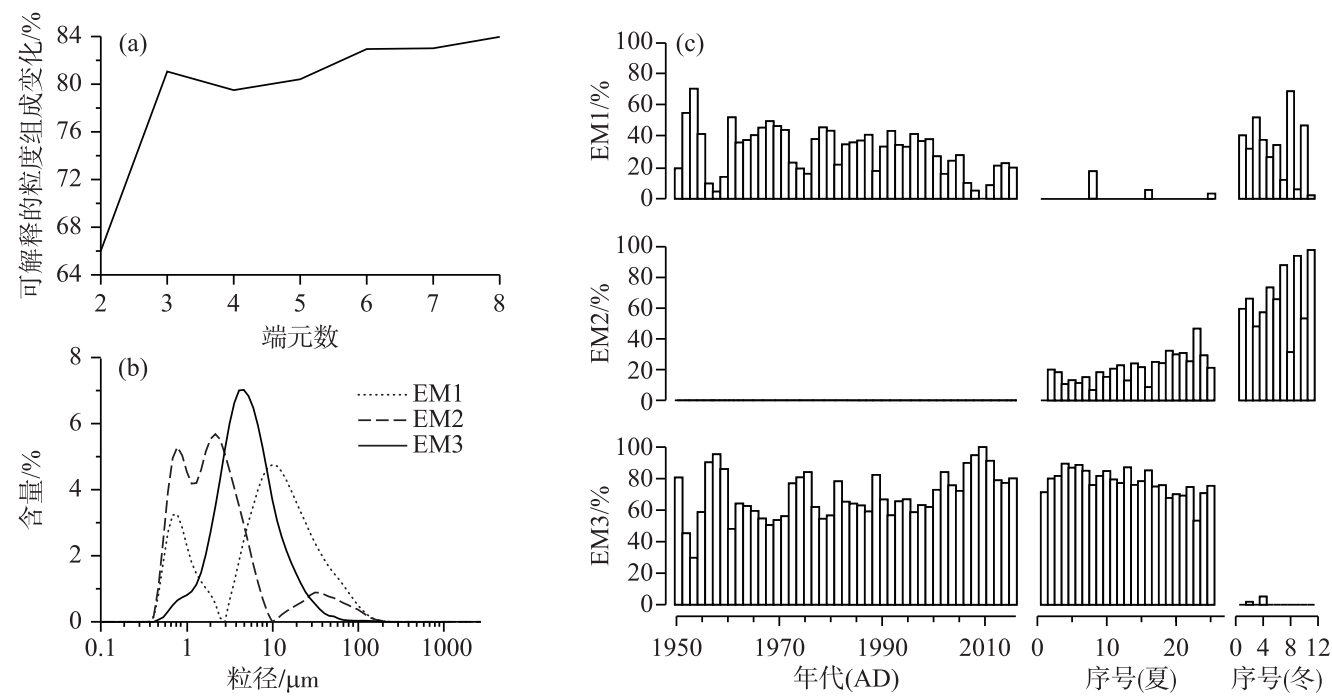

图 5 端元数与可解释的粒度组成变化间的关系 (a)、基于巴松措沉积物岩芯和捕获器粒度数据的 端元组分分析结果 (b) 以及各组分在样品中的分布情况 (c)

Fig.5 The relationship between the number of members and the explained variation of grain size compositions (a), the result of EMMA based on the grain size of the core and the sediment traps in Lake Basomtso(b) and the distribution of each member (c)

\section{3 磁化率结果}

巴松措沉积物样品高低频磁化率呈现同步变化趋势, 数值介于 $18 \times 10^{-8} \sim 22 \times 10^{-8} \mathrm{~m}^{3} / \mathrm{kg}$ 之间 (图 $6 \mathrm{~d}$ ). 样品磁化率数值整体偏低, 1950-1970 年间呈明显上升趋势, 幅度较大, 1970-1990 年期间磁化率整体偏高 且波动幅度较小, 1990- 2000 年间磁化率呈明显的下降趋势, 自 2000 年以来波动幅度逐渐增大.

\section{4 有机碳、氮结果}

巴松措沉积物中 TOC 含量变化介于 $0.6 \% \sim 1.1 \%$ 之间, 最小值为 1950 年的 $0.64 \%$, 在 2015 年达到最大 值 $1.08 \%$ (图 6a) ; 总氮含量 $(\mathrm{TN}$ ) 变化介于 $0.03 \% \sim 0.06 \%$ 之间, 同样在 1950 年出现最小值 $0.03 \%$, 最大值 $0.06 \%$ 出现在 2013 年 (图 6b). 沉积物岩芯中总有机碳、氮含量整体变化趋势具有较好的一致性, 自 1950 年 以来均呈现逐渐上升的趋势. 另一方面, 样品 $\mathrm{C} / \mathrm{N}$ 比值在 $15 \sim 22$ 之间波动变化, 并且在过去 60 年呈明显降 低趋势(图 6c). 


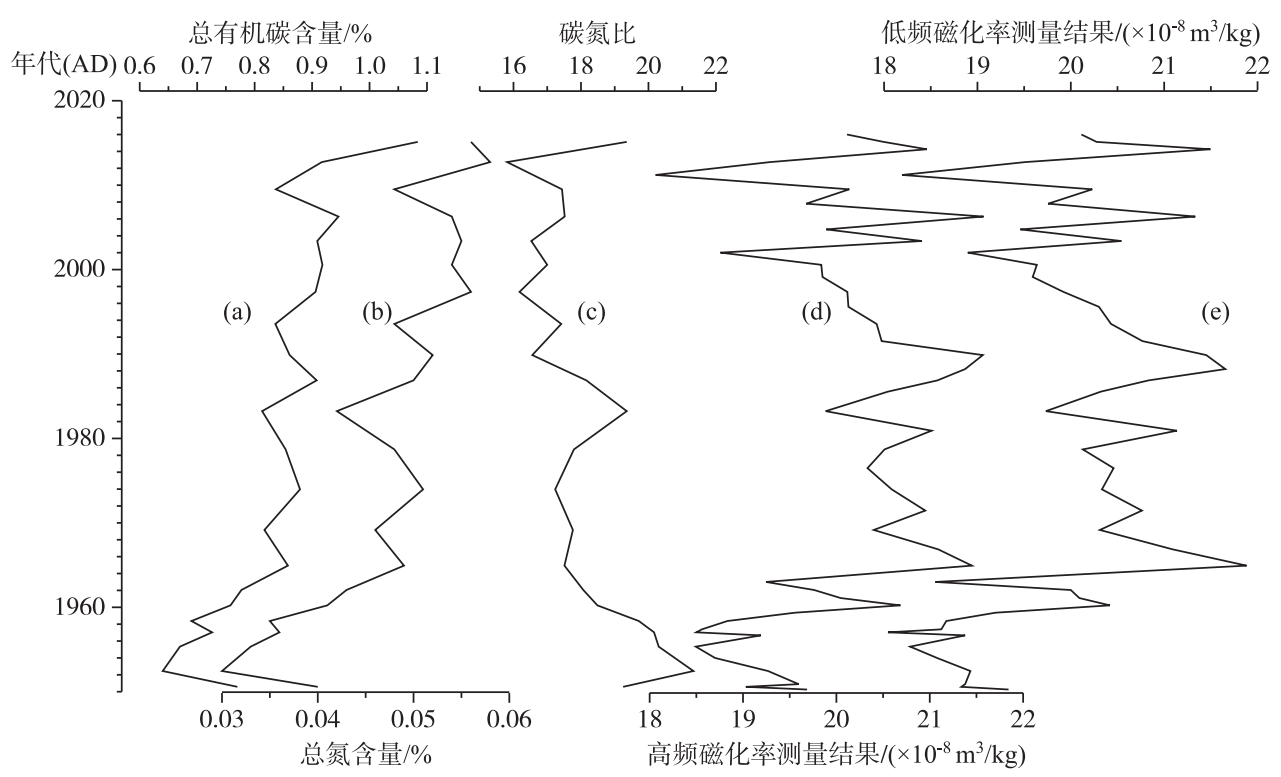

图 6 巴松措沉积物总有机碳 (a)、总氮 (b)、碳氮比 (c) 以及高频 (d)、低频 (e) 磁化率结果

Fig.6 Results of total organic carbon content (a), total nitrogen content (b), carbon-nitrogen ratio (c), and high-frequency (d)/low-frequency (e) magnetic susceptibilities in the sediment of Lake Basomtso

\section{4 讨论}

\section{1 沉积物粒度组成及其气候环境意义}

沉积物颗粒的大小称为粒度,是判断搬运方式、沉积物来源以及反映动力条件等信息的重要指标, 对沉 积学的研究具有十分重要的意义, 因此在恢复过去气候变化历史的研究中被广泛应用 ${ }^{[32]}$. 近年来的研究当 中,藏南沉措沉积物粒度揭示了其所在地区过去 1400 年间的干湿演变 ${ }^{[33]}$, 苏干湖粒度分布特征能够指示其 沉积物来源 ${ }^{[34]}$, 达里湖沉积物粒度分布特征揭示了全新世期间湖水水位变化 ${ }^{[35]}$. 粒度分布是对沉积物的搬 运方式、动力条件以及沉积环境等影响因素的综合反映 ${ }^{[36]}$. 研究表明, 水动力条件较强时, 沉积物颗粒较 粗, 反之水动力条件越弱沉积物颗粒越小 ${ }^{[37]}$. 由于粒度组成受搬运方式、沉积环境动力条件等多因素综合 影响, 具有多解性, 需要结合其他指标进行气候重建. 由于端元组分分析具有普适性、建模算法灵活等特点, 能够在不同沉积环境应用 ${ }^{[7]}$, 因此其在利用粒度恢复气候的研究中逐渐受到越来越多学者的重视. 例如: 库 赛湖 ${ }^{[38]}$ 、查干淖尔 ${ }^{[39]}$ 以及柴达木盆地河相沉积物 ${ }^{[40]}$ 粒度的端元组分分析结果有效地解释了沉积物各组分 的来源、搬运方式以及环境变化等信息.

从端元组分分析结果来看,巴松措沉积物中 EM1 组分主要在岩芯和冬季现代沉积物中出现较多,而夏 季现代沉积物中很少出现 (图 5c), 该组分的粒径分布主要集中在 3 200 $\mu \mathrm{m}$ 之间的主峰, 峰值大约在 10 $20 \mu \mathrm{m}$ 左右 (图 5b). Maarten 等 ${ }^{[41]}$ 对晚第四纪黄土高原风成沉积物粒度的研究, 也出现了类似峰值的端元 组分, 其分布范围在 $100 \mu \mathrm{m}$ 以内, 峰值同样在 $10 \mu \mathrm{m}$ 以上接近 $20 \mu \mathrm{m}$ 处,并指出该组分是来自远处细粒风 成沉积物产生的分选性较好的持续悬浮粉尘. 另外, 青藏高原的冬给措那湖泊沉积物的端元组分分析结果 中同样发现峰值位于 $\varphi=6(10 \sim 20 \mu \mathrm{m})$ 的细颗粒组分, 该组分一般是通过风力搬运自湖泊周围地区的风成 沉积物 ${ }^{[7]}$. 因此, 可以推断巴松措沉积物中 EM1 组分可能是悬浮在空中并由风力搬运而来的物质; 另外, 考 虑到巴松措位于青藏高原东南部,并且 EM1 输人主要集中在冬季, 因此 EM1 组分有可能是由冬季风带来的 高原内部戈壁、荒漠上空的粉尘. 同时还发现,沉积物中 EM1 组分含量的变化 (图 7a) 与林芝气象站记录的 1954-2016 年间的平均风速变化趋势 (图 7b) 具有很好的一致性, 可以进一步确认 EM1 组分是由风力搬运 而来的成分. 此外, 青藏高原地区现代风场图表明林芝地区冬季主要受源至高原南部的气流控制, 且平均风 
速的年际变化与高原南部站点一致(图 1). 因此, 我们认为 EM1 组分是在冬季由风力搬运自青藏高原南部 和西南部戈壁、荒漠上空的粉尘.

EM2 组分为 3 个组分中颗粒最细的一个, 主峰峰值位于 $2 \sim 3 \mu \mathrm{m}$ 左右, 成分主要是黏土 (图 $5 \mathrm{~b}$ ). 并且 EM2 组分仅在捕获器中出现, 具有随深度增大含量减少的特征 (图 5c). 根据殷志强等 ${ }^{[42]}$ 对安固里淖等多处 湖泊、河流沉积物粒度的研究, 湖泊沉积物粒度主要分为 $0 \sim 1 、 2 \sim 10 、 10 \sim 70 、 70 \sim 150 、 150 \sim 700$ 和 $>700 \mu \mathrm{m}$ 共 6 个组分, 且其中前 4 个组分均为悬浮组分, 与巴松措沉积物中 EM2 组分粒径范围一致. 除此之外, 王艳 杰等 ${ }^{[43]}$ 在对广州流溪河水库沉积物的端元组分分析中, 同样出现了峰值位于 $\varphi=8.5$ 左右 $(\approx 3 \mu \mathrm{m})$ 的细颗 粒组分, 而该组分被指出是悬浮在水中的细颗粒物质. 因此, 仅在捕获器样品中出现的 EM2 组分, 其主要是 来自于悬浮于水中未沉积到湖底的悬浮物.

EM3 组分几乎仅出现在岩芯和夏季的现代沉积物中, 在冬季几乎没有收集到 EM3 组分, EM3 粒径分布 的峰值位于 $6 \mu \mathrm{m}$ 左右, 且呈现出近似标准的正态分布, 分选性较好, 指示 EM3 组分可能经过了长途的搬运 (图 5b). 在李久乐 ${ }^{[44]}$ 对枪勇措冰前湖沉积物的粒度研究中, 冰碛细粒物的第一个主峰分布范围在 $30 \mu \mathrm{m}$ 以 下, 峰值位于 $6 \sim 7 \mu \mathrm{m}$ 左右, 与该组分类似. 而且由于巴松措为冰川补给, 因此 EM3 组分其物质来源可能是 冰川融化带来的碎屑, 而这些碎屑物质的搬运方式则是河流搬运, 我们认为 EM3 是通过径流带人湖泊的颗 粒组分. 但由于其输人量受到径流量控制, 而径流量又分别受到降水与冰雪融水的影响, 导致 EM3 组分变 化对气候因素的响应过程更为复杂.

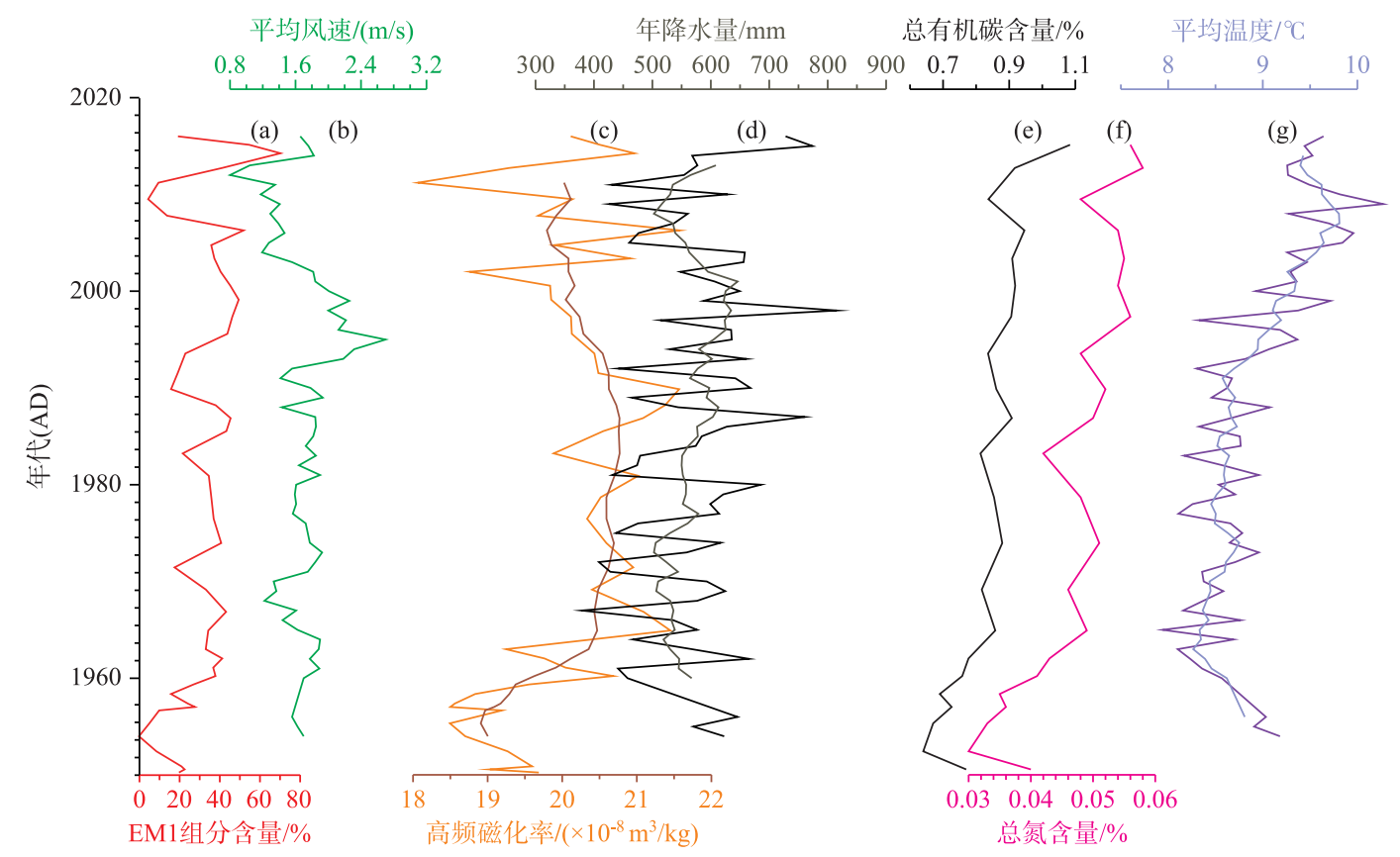

图 7 各沉积学指标测量结果与林芝气象站器测气象数据对比

Fig.7 Comparison of sedimentary proxies with meteorological data from Nyingchi Station

综上所述,巴松措沉积物粒度组成一定程度上可反映湖泊中不同组分的搬运方式和来源: EM1 组分主 要是由风力搬运自青藏高原南部、西南部大气上空的悬浮颗粒; EM3 则主要是由夏季冰雪融水以及降水等 因素综合影响下的径流搬运而来的冰川碎屑物质; 另外, 颗粒最细的 EM2 组分未出现在岩芯的沉积物中, 主 要是来自湖水中悬浮的细颗粒物质.

\section{2 磁化率及降水变化}

磁化率指物质在磁场中被磁化的程度, 是用于恢复气候的重要指标之一, 并且磁化率的测量简单, 快 捷, 经济且不具有破坏性, 因此在恢复气候的研究中也被广泛应用 ${ }^{[45]}$. 如呼伦湖湖泊沉积物记录的磁化率 
变化情况, 可以揭示湖面的变化历史, 进而反映其所在地区的干湿变化情况 ${ }^{[46]}$. 湖泊沉积物当中的磁性来 自其中的磁性矿物, 而天然湖泊中的磁性矿物主要是由其流域内的侵蚀作用产生, 并通过径流搬运进人到 湖泊当中, 因此, 降水量会同时通过侵蚀速率和地表径流的搬运能力两方面来影响磁化率的变化 ${ }^{[47-49]}$. 当磁 化率较高时, 流域内侵蚀以及径流的搬运能力较强, 反映较为暖湿的环境; 反之, 磁化率较低时表明流域内 侵蚀搬运能力较弱, 反映较干冷的环境. 与其他天然湖泊一样, 巴松措湖泊沉积物中磁性矿物产生自流域内 的侵蚀作用, 由地表径流输人到湖中, 而侵蚀速率以及磁性矿物的输人量又与降水量密切相关. 研究表明, 西藏地区以自然侵蚀为主, 其中水力侵蚀强度地区差异较大, 强度自巴松措所在的藏东南地区向西北递 减 ${ }^{[50-51]}$, 降水是地表侵蚀的主要影响因素之一 ${ }^{[52]}$. 因此认为巴松措湖泊沉积物中磁性矿物含量的变化主要 反映其流域内降水量的变化. 通过对比发现, 巴松措湖泊沉积物磁化率的变化趋势 (图 7c) 与林芝气象站记 录的降水量 (图 7d) 呈现出较好的同步性. 因此我们可以进一步确定, 巴松措湖泊沉积物中磁化率的波动, 是对该地区降水量变化的反映.

\section{3 总有机碳、氮含量}

沉积物中的 TOC 是用于描述沉积物中有机质丰度的最基本参数, 既可以反映沉积物中有机物含量的多 少, 又能反映沉积环境对有机物保存能力的强弱. 而有机质的生成又与温度、湿度等环境因素相关, 因此 TOC 可以作为重要的环境指标, 应用于气候重建的研究中 ${ }^{[53-56]}$.

沉积物中的碳氮比 $(\mathrm{C} / \mathrm{N})$ 则是指沉积物中 TOC 与 TN 含量的比值, 是用于判断沉积物来源的重要指标 之一 ${ }^{[53]}$. 湖泊中有机碳和氮的来源主要有湖泊自身生产者和外力搬运的陆源碎屑两种, 由于水生植物蛋白 质含量较纤维含量偏高, 因此湖泊自生有机质 $\mathrm{C} / \mathrm{N}$ 比值较低; 而陆源植物则相反, 有机质 $\mathrm{C} / \mathrm{N}$ 比值偏高 ${ }^{[10]}$. 因此, 沉积物 TOC 与 TN 的含量以及比值, 可以反映湖泊自身生产力大小以及沉积物来源 ${ }^{[54]}$. 如, 鄱阳湖表 层沉积物的 $\mathrm{C} / \mathrm{N}$ 比值揭示了有机碳来自陆生或水生植物 ${ }^{[55]}$. 巴松措湖泊沉积物的 $\mathrm{C} / \mathrm{N}$ 比值波动介于 $15 \sim$ 20 之间,多在 20 以下, 所以可以判断出巴松措湖泊沉积物中有机质同时包括湖泊内的水生生产者以及流域 内的陆源生产者. 另外, 巴松措沉积物中 $\mathrm{C} / \mathrm{N}$ 比值呈现出明显的降低趋势, 表明湖泊内源有机质所占比例逐 步增加 (图 6c).

湖泊沉积物中有机碳含量的变化可以敏感的记录历史时期气候变化特征, 尤其是对于高寒地区湖泊, 温度变化很大程度上影响着湖泊和流域内初级生产力的变化. 例如, 在对达布逊湖北雅丹剖面 ${ }^{[56]}$ 、小喀 湖 ${ }^{[57]}$ 、青海湖 ${ }^{[58]}$ 以及安固里淖 ${ }^{[59]}$ 等沉积物的研究中, TOC 被用来恢复了过去几百甚至上千年的温度变化. 近年来, 巴松措湖泊沉积物中的 TOC 和 TN 含量逐渐增高, 结合近年 $\mathrm{C} / \mathrm{N}$ 比值逐渐降低的情况来看, 巴松措 湖泊自身初级生产力在逐渐提高. 另外由于巴松措水体面积较大, 湖水较深, 最深处超过 $120 \mathrm{~m}$, 水位的年际 变化以及湖泊面积变化对 TOC 含量的影响相对有限. 因此我们认为巴松措湖泊沉积物的 TOC 含量变化主 要受区域温度的影响. 同时发现巴松措湖泊沉积物中 TOC、TN 含量变化 (图 7e,f) 与林芝气象站记录的此地 区平均温度的波动 (图 7g) 具有较好的一致性, 相关系数均为 0.705 且通过显著性检验 $(P<0.001$ ). 因此, 我 们认为巴松措沉积物中 TOC、TN 含量的变化以及湖泊的初级生产力主要受该地区温度的影响.

\section{5 结论}

通过对巴松措湖泊沉积物岩芯和现代沉积物进行粒度、磁化率、有机质含量等测试, 综合实验数据进行 分析, 并将各项指标的实验数据与巴松措所在地区的气象数据进行对比, 得到以下主要结论:

1)巴松措沉积物粒度组成可以有效地指示沉积物来源及其搬运过程,端元组分分析中的 EM1 组分指 示由风力搬运自青藏高原南部和西南部上空悬浮于大气中的颗粒, 仅出现在捕获器收集到的现代沉积物中 的 EM2 组分主要是湖水中的悬浮颗粒, EM3 组分是由径流带来的冰川碎屑物质,而其含量变化是受温度 (冰雪融水) 与降水综合影响的结果.

2) 巴松措湖泊沉积物岩芯磁化率变化可以反映流域内侵蚀速率及搬运过程的变化, 指示流域对降水响 应结果.

3 ) 湖泊沉积物中有机质含量 (TOC、TN) 近年来呈现出明显的上升趋势, 且湖泊内源有机质成分明显增 加, 其变化主要是对林芝地区温度变化尤其是近年来全球变暖过程的反映. 由此可见,巴松措现代沉积物指 
标可以有效地指示该地区气候演化历史,利用该湖泊沉积物可以获取更长时间尺度区域气候演化记录.

\section{6 参考文献}

[ 1 ] Shen J. Progress and prospect of palaeolimnology research in China. J Lake Sci, 2009, 21 (3) : 307-313. DOI : 10.18307/ 2009.0301. [沈吉. 湖泊沉积研究的历史进展与展望. 湖泊科学, 2009, 21(3) : 307-313.]

[ 2 ] Last WM, Smol JP, Last WM et al. Tracking environmental change using lake sediments. Volume 1: basin analysis, coring, and chronological techniques. Freshwater Biology, 2001, 49(5) : 678-679.

[ 3 ] Liu X, Dong H, Yang X et al. Late Holocene forcing of the Asian winter and summer monsoon as evidenced by proxy records from the northern Qinghai-Tibetan Plateau. Earth \& Planetary Science Letters, 2009, 280(1) : 276-284. DOI: 10. 1016/j.epsl.2009.01.041.

[ 4 ] An Z, Clemens SC, Shen J et al. Glacial-interglacial Indian summer monsoon dynamics. Science, 2004, 6043( 333 ) : 719 723. DOI: $10.1126 /$ science.1203752.

[ 5 ] Shen J, Liu X, Wang S et al. Palaeoclimatic changes in the Qinghai Lake area during the last 18,000 years. Quaternary International, 2005, 136(1) : 131-140. DOI: 10.1016/j.quaint.2004.11.014.

[ 6 ] Jia TF, Dai XR, Zhang WG et al. Sediment records in Chaohu Lake and its significance on environmental change in Holocene. Scientia Geographica Sinica, 2006, (6) : 706-711. [贾铁飞, 戴雪荣, 张卫国等. 全新世巢湖沉积记录及其环 境变化意义. 地理科学, 2006, (6) : 706-711.]

[ 7 ] Dietze E, Kai H, Diekmann B et al. An end-member algorithm for deciphering modern detrital processes from lake sediments of Lake Donggi Cona, NE Tibetan Plateau, China. Sedimentary Geology, 2012, 243(1) : 169-180. DOI: 10.1016/ j. sedgeo.2011.09.014.

[ 8 ] Li ZG. Glaciers and lakes changes on the Qinghai-Tibet Plateau under climate change in the past 50 years. Journal of Natural Resources, 2012, (8) : 1431-1443. [李治国. 近 50a 气候变化背景下青藏高原冰川和湖泊变化. 自然资源学 报, 2012, (8): 1431-1443.]

[ 9 ] Wu D, Zhou A, Liu J et al. Changing intensity of human activity over the last 2,000 years recorded by the magnetic characteristics of sediments from Xingyun Lake, Yunnan, China. Journal of Paleolimnology, 2015, 53(1) : 47-60. DOI: 10. 1007/s10933-014-9806-2.

[10] Meyers PA, Lallier-Vergés E. Lacustrine sedimentary organic matter records of late quaternary paleoclimates. Journal of Paleolimnology, 1999, 21(3) : 345-372. DOI: 10.1023/A:1008073732192.

[11] Feng SM, liu DY, Li DJ et al. Analysis on the temporal and spatial distribution of the primary productivity and its influencing factors in Lake Taiping(Reservoir), Anhui Province. J Lake Sci, 2016, 28(6) : 1361-1370. DOI: 10.18307/2016. 0622. [冯世敏, 刘冬燕, 李东京等. 安徽太平湖水库初级生产力时空分布及分析. 湖泊科学, 2016, 28(6): 1361-1370.]

[12] $\mathrm{Hu} \mathrm{Y,} \mathrm{Yu} \mathrm{H,} \mathrm{Li} \mathrm{ZQ.} \mathrm{Effects} \mathrm{of} \mathrm{wet} \mathrm{deposition} \mathrm{on} \mathrm{water} \mathrm{quality} \mathrm{and} \mathrm{primary} \mathrm{productivity} \mathrm{in} \mathrm{the} \mathrm{Meiliang} \mathrm{bay} \mathrm{of} \mathrm{Lake} \mathrm{Tai.}$ Resources and Environment in the Yangtza Basin, 2014, 23(1) : 75-80. DOI: 10.11870/cjlyzyyhj201401011. [胡洋, 余 辉, 李中强. 湿沉降对湖泊水质及初级生产力的影响. 长江流域资源与环境, 2014, 23(1) : 75-80.]

[13] Chen CH, Wang JZ, Zhu C et al. Relationship between the sediment pigment records of Lake Lugu and the regional climate change over the last 200 a. J Lake Sci, 2012, 24( 5) : 780-788. DOI: 10.18307/2012.0520. [ 陈传红, 汪敬忠, 朱 迟等. 近 $200 \mathrm{a}$ 来沾沽湖沉积物色素记录与区域气候变化的关系. 湖泊科学, 2012, 24(5): 780-788.]

[14] Dong SP, Li ZL, Chen Q et al. Total organic carbon and its environmental significance for the surface sediments in groundwater recharged lakes from the Badain Jaran Desert, Northwest China. Journal of Limnology, 2018, 77 ( 1) : 121-129. DOI: $10.4081 /$ jlimnol.2017.1667.

[15] Li ZL, Wei ZQ, Dong SP et al. The paleoenvironmental significance of spatial distributions of grain size in groundwater-recharged lakes: A case study in the hinterland of the Badain Jaran Desert, northwest China. Earth Surface Processes and Landforms, 2017, 43(2) : 363-372. DOI: 10.1002/esp.4248.

[16] Chen JA, Wang GJ. Sediment particle size distribution and its environmental significance in Lake Erhai, Yunnan province. Acta Mineralogica Sinica, 1999, (2) : 175-182. [陈敬安, 万国江. 云南洱海沉积物粒度组成及其环境意义辨识. 矿 物学报, 1999, (2): 175-182.] 
[17] Xie YY, Wang QL, Li CA et al. Climatic implication of grain size from lacustrine sediments: A case study of Jiangling section, Jianghan plain, China. Geological Science and Technology Information, 2004, 23(4): 41-43. [谢远云, 王秋良, 李长安等. 湖泊沉积物粒度的气候指示意义一一以江汉平原江陵剖面为例. 地质科技情报, 2004, 23(4) : 41-43.]

[18] Zhang ST, Song XL, Zhang ZX et al. The changing of mineral composition and environmental significance in surface sediments of Xingyun Lake. Advances in Earth Sciences, 2003, 18(6): 928-932. [张世涛, 宋学良, 张子雄等. 星云湖表层 沉积物矿物组成及其环境意义. 地球科学进展, 2003, 18(6) : 928-932.]

[19] Zhang JF, Zhou LP, Yao SC et al. Radiocarbon and optical dating of lacustrine sediments - A case study in Lake Gucheng. Quaternary Sciences, 2007, 27(4): 522-528. [张家富, 周力平, 姚书春等. 湖泊沉积物的 ${ }^{14} \mathrm{C}$ 和光释光测 年——以固城湖为例. 第四纪研究, 2007, 27(4): 522-528.]

[20] Dong YY, Jin F, Huang JH. Poyang Lake sediments grain size characteristics and its tracing implication for formation and evolution processes. Geological Science and Technology Information, 2011, (2): 57-62. [董延钰, 金芳, 黄俊华. 鄱阳 湖沉积物粒度特征及其对形成演变过程的示踪意义. 地质科技情报, 2011, (2) : 57-62.]

[21] Yao TD, Liu XD, Wang NL. The extent of climate change in the Qinghai-Tibet Plateau.Chinese Science Bulletin, 2000, (1) : 98-106. [姚檀栋, 刘晓东, 王宁练. 青藏高原地区的气候变化幅度问题. 科学通报, 2000, (1) : 98-106. ]

[22] Ni J. A simulation of biomes on the Tibetan Plateau and their responses to global climate change. Mountain Research \& Development, 2000, 20(1) : 80-89. DOI: 10.1659/0276-4741 (2000) 020[0080:ASOBOT] 2.0.CO;2.

[23] Xu XK, Chen H, Levy JK et al. Spatiotemporal vegetation cover variations in the Qinghai-Tibet Plateau under global climate change. Chinese Science Bulletin, 2008, 53(6) : 915-922. DOI: 10.1007/s11434-008-0115-x.

[24] Li K, Liu XQ, Wang YB et al. Late Holocene vegetation and climate change on the southeastern Tibetan Plateau: Implications for the Indian Summer Monsoon and links to the Indian Ocean Dipole. Quaternary Science Reviews, 2017, 177: 235 245. DOI: $10.1016 /$ j.quascirev.2017.10.020.

[25] Zhang XS ed. Chinese vegetation and its geographical Pattern: Vegetation Map of the People's Republic of China ( 1 : 1000000). Beijing: Geological Publishing House, 2007: 834-835. [张新时. 中国植被及其地理格局: 中华人民共和 国植被图 $(1: 1000000)$ 说明书. 北京: 地质出版社, 2007: 834-835.]

[26] Wang Y, Bekeschus B, Handorf D et al. Coherent tropical-subtropical Holocene see-saw moisture patterns in the Eastern Hemisphere monsoon systems. Quaternary Science Reviews, 2017, 169: 231-242. DOI: 10.1016/j.quascirev.2017.06.006.

[27] Liu EF, Xue B, Yang XD et al. ${ }^{137} \mathrm{Cs}$ and ${ }^{210} \mathrm{~Pb}$ chronology for modern lake sediment: A case study of Chaohu Lake and Taibai Lake. Marine Geology \& Quaternary Geology, 2009, (6) : 89-94. [刘恩峰, 薛滨, 羊向东等. 基于 (210) Pb 与 (137) Cs 分布的近代沉积物定年方法——以巢湖、太白湖为例. 海洋地质与第四纪地质, 2009, (6): 89-94.]

[28] Dietze M, Dietze E. EMMAgeo: End-member modelling algorithm and supporting functions for grain-size analysis. 2013.

[29] Wang GJ. ${ }^{210} \mathrm{~Pb}$ dating for recent sedimentation. Quaternary Sciences, 1997, (3) : 230-239. [万国江. 现代沉积的 ${ }^{210} \mathrm{~Pb}$ 计年. 第四纪研究, 1997, (3) : 230-239.]

[30] Jin AC, Jiang QF, Chen Y et al. ${ }^{210} \mathrm{~Pb}$ and ${ }^{137} \mathrm{Cs}$ dating and modern sedimentation rate in the Wulungu Lake, Xinjiang. Geoscience, 2010, (2) : 377-382. [ 金爱春, 蒋庆丰, 陈晔等. 新疆乌伦古湖的 ${ }^{210} \mathrm{~Pb} 、{ }^{137} \mathrm{Cs}$ 测年与现代沉积速率. 现 代地质, 2010, (2):377-382.]

[31] Weltje GJ. End-member modeling of compositional data: Numerical-statistical algorithms for solving the explicit mixing problem. Mathematical Geology, 1997, 29(4) : 503-549. DOI: 10.1007/BF02775085.

[32] Friedman GM, Sanders JE eds. Principles of Sedimentology. New York: Wiley, 1978: 2-4.

[33] Wang JB, Zhu LP. Grain-size characteristics and their paleo-environmental significance of Chen Co lake sediments in Southern Tibet. Progress in Geography, 2002, (5) : 459-467. [王君波, 朱立平. 藏南沉错沉积物的粒度特征及其古 环境意义. 地理科学进展, 2002, (5): 459-467.]

[34] Qiang M, Chen F, Zhang J et al. Grain size in sediments from Lake Sugan: a possible linkage to dust storm events at the northern margin of the Qinghai-Tibetan Plateau. Environmental Geology, 2007, 51(7) : 1229-1238. DOI: 10. 1007/ s00254-006-0416-9.

[35] Xiao J, Si B, Zhai D et al. Hydrology of Dali Lake in central-eastern Inner Mongolia and Holocene East Asian monsoon variability. Journal of Paleolimnology, 2008, 40 (1) : 519-528. DOI: 10.1007/s10933-007-9179-x.

[36] Xiao CX, Li ZZ. The research summary of grain size analysis and its application in the sedimentation. Journal of Xinjiang Normal University: Natural Sciences Edition, 2006, (3) : 118-123. [肖晨曦, 李志忠. 粒度分析及其在沉积学中应用 
研究. 新疆师范大学学报: 自然科学版, 2006, (3) : 118-123.]

[37] Ding XG, Ye SY, Gao ZJ. Development and applications of grain size analysis technique. World Geology, 2005, (2): 203-207. [丁喜桂，叶思源，高宗军. 粒度分析理论技术进展及其应用. 世界地质，2005，(2) : 203-207.]

[38 ] Liu XQ, Yao B, Yang B. Grain size distribution of aeolian and lacustrine sediments of Kusai Lake in the Hoh Xil region of the northern Qinghai-Tibetan Plateau. Quaternary Sciences, 2010, (6): 1193-1198. [刘兴起, 姚波, 杨波. 青藏高原北 部可可西里库赛湖沉积物及风成物的粒度特征. 第四纪研究, 2010, (6) : 1193-1198.]

[39] Han P, Liu XQ. The climate evolution inferred from Bhagan-Nuur in middle-east part of inner Mongolia since the last 7000 years. Quaternary Sciences, 2017, (6) : 1381-1390. [韩鹏, 刘兴起. 内蒙古中东部查干淖尔湖流域 7000 年以来的气 候演变. 第四纪研究, 2017, (6) : 1381-1390.]

[40] Nie JS, Li M. A grain size study on late Miocene Huaitoutala section, Ne qaidam basin, and implications for Asian monsoon evolution. Quaternary Sciences, 2017, (5) : 1017-1026. [聂军胜, 李曼. 柴达木盆地晚中新世河湖相沉积物粒 度组成及其古环境意义. 第四纪研究, 2017, (5) : 1017-1026.]

[41] Prins MA, Vriend M, Nugteren G et al. Late Quaternary aeolian dust input variability on the Chinese Loess Plateau: inferences from unmixing of loess grain-size records. Quaternary Science Reviews, 2007, 26(1) : 230-242. DOI: 10.1016/j. quascirev.2006.07.002.

[42] Yin ZQ, Qin XG, Wu JS et al. Multimodal grain-size distribution characteristics and formation mechanism of lake sediments. Quaternary Sciences, 2008，(2) : 345-353. [ 殷志强, 秦小光, 吴金水等. 湖泊沉积物粒度多组分特征及其成 因机制研究. 第四纪研究, 2008, (2): 345-353.]

[43] Wang YJ, Tang HQ, Jiang SJ. End-member modeling analysis of sediment grain-size and implication for depositional dynamics in Liuxihe reservoir, Guangzhou, China. Journal of Chengdu University of Technology: Sci \& Technol, 2015, (4) : 476-483. [王艳杰, 唐红渠, 姜仕军. 广州流溪河水库沉积物粒度端元模型分析及其沉积动力学意义. 成都理工大 学学报: 自然科学版, 2015, (4): 476-483.]

[44] Li JL, Xu BQ, Lin SB et al. Glacier and climate changes over the past millennium recorded by proglacial sediment sequence from Qiangyong Lake, Southern Tibetan Plateau. Journal of Earth Sciences and Environment, 2011, (4): 402411. [李久乐, 徐柏青, 林树标等. 青藏高原南部枪勇错冰前湖泊沉积记录的近千年来冰川与气候变化. 地球科 学与环境学报, 2011, (4): 402-411.]

[45] Wang J, Liu ZC, Jiang WY et al. A relationship between susceptibility and grain-size and minerals, and their paleo-environmental implications. Acta Geographica Sinica, 1996, (2) : 155-163. [王建, 刘泽纯, 姜文英等. 磁化率与粒度、矿 物的关系及其古环境意义. 地理学报, 1996, (2) : 155-163.]

[46] Hu SY, Wang SM, Apple E et al. Environmental magnetic mechanism of magnetic susceptibility change of lake Hulun Lake sediments. Science in China: Series D: Earth Sciences, 1998，(4) : 334-339. [胡守云, 王苏民, Appel E 等. 呼伦 湖湖泊沉积物磁化率变化的环境磁学机制. 中国科学: D 辑: 地球科学, 1998, (4) : 334-339.]

[47] Yao Y, Zhang EL, Shen J et al. Human activities indicated by lacustrine deposition in the region of Shudu Lake. Marine Geology \& Quaternary Geology, 2007, (5) : 115-120. [姚远, 张恩楼, 沈吉等. 云南属都湖流域人类活动的湖泊沉 积响应. 海洋地质与第四纪地质, 2007, (5): 115-120.]

[48] Lu MH, Wang HY, Cai YL. Soil erosion investigations based on analyses of sediment in lakes and reservoirs. Bulletin of Soil and Water Conservation, 2007, (3) : 36-41, 58. [吕明辉, 王红亚, 蔡运龙. 基于湖泊(水库)沉积物分析的土 壤侵蚀研究. 水土保持通报, 2007, (3): 36-41, 58.]

[49] Tan JF, Xiao XY, Li YL. Late Holocene climatic change revealed by sediment records in Gegongcuonaka Lake, northwestern Yunnan Province. Quaternary Sciences, 2018, 38(4) : 900-911. [谭金凤, 肖霞云, 李艳玲. 滇西北格贡错那卡湖 沉积记录揭示的晚全新世气候变化. 第四纪研究, 2018, 38(4) : 900-911.]

[50] Liu SZ, Zhang JG, Gu SX. Study on the soil erosion types in Tibet. Journal of Mountain Research, 2006, (5) : 592-596. [刘淑珍, 张建国，幸世贤. 西藏自治区土壤侵蚀类型研究. 山地学报，2006，(5): 592-596.]

[51] Yan D, Fan JR, Guo FF et al. Spatiotemporal distribution of precipitation erosivity in Tibet Autonomous Region. Bulletin of Soil and Water Conservation, 2010, (4) : 17-21, 249. [严冬, 范建容, 郭芬芬等. 西藏地区降水侵蚀力时空分布研 究. 水土保持通报, 2010, (4): 17-21, 249.]

[52] Liu BT, Tao HP, Song CF et al. Temporal and spatial variations of rainfall erosivity in Southwest China from 1960 to 2009. Advance in Earth Sciences, 2012, (5): 499-509. [刘斌涛, 陶和平, 宋春风等. 我国西南山区降雨侵蚀力时空变化 
趋势研究. 地球科学进展, 2012, (5): 499-509.]

[53] Krishnamurthy RV, Bhattacharya SK, Kusumgar S. Paleoclimatic changes deduced from ${ }^{13} \mathrm{C} /{ }^{12} \mathrm{C}$ and $\mathrm{C} / \mathrm{N}$ ratios of Karewa lake sediments, India. Nature, 1986, 323(6084) : 150-152. DOI: 10.1038/323150a0.

[54] Chen JA, Wan GJ, Wang FS et al. The study of carbon environment record of modern sediments in lakes. Scientia Sinica Terrae $(D), 2002,(1): 73-80$. [ 陈敬安, 万国江, 汪福顺等. 湖泊现代沉积物碳环境记录研究. 中国科学: D 辑, 2002, (1): 73-80.]

[55] Wang ML, Lai JP, Hu KT et al. Compositions and sources of stable organic carbon and nitrogen isotopes in surface sediments of Poyang Lake. China Environmental Science, 2014, (4): 1019-1025. [王毛兰, 赖建平, 胡珂图等. 鄱阳湖表 层沉积物有机碳、氮同位素特征及其来源分析. 中国环境科学, 2014, (4) : 1019-1025.]

[56] Li YH, Zheg MP, Zhao XQ et al. Sedimentary characteristics and environmental significance of Yadan Profile in the Northern Dabsun Lake of Qaidam Basin, China. Journal of Earth Sciences and Environment, 2017, (6) : 787-794. [李玉辉, 郑绵平, 赵小庆等. 柴达木盆地达布逊湖北雅丹剖面沉积特征及其环境意义. 地球科学与环境学报, 2017, (6): 787-794. ]

[57] Li SH, Jin ZD, Zhang F et al. Temperature variation in Muztag Ata region over the past 200 years recorded by total organic carbon of lake sediments in Little Kalakul Lake. Journal of Earth Environment, 2018, (2) : 137-148. DOI: 10.7515/ JEE182010. [李帅华, 金章东, 张飞等. 小喀湖有机碳记录的慕土塔格地区过去 200 年温度变化. 地球环境学报, 2018, (2): 137-148.]

[58] Zhang EL, Shen J, Wang SM et al. Climate and environment change during the past 900 years in Qinghai Lake. J Lake $S c i, 2002$, (1) : 32-38. DOI: 10.18307/2002.0105. [张恩楼, 沈吉, 王苏民等. 青海湖近 900 年来气候环境演化的 湖泊沉积记录. 湖泊科学, 2002, (1) : 32-38.]

[59] Ma L, Wu JL. Environmental significance from organic carbon and its isotope of Angulinao Lake sediment. Journal of Natural Resources, 2009, 24 (6) : 1099-1104. DOI : 10.11849/zrzyxb.2009.06.017. [马龙, 吴敬禄. 安固里淖湖积物中总 有机碳含量及其碳同位素的环境意义. 自然资源学报, 2009, 24(6) : 1099-1104.] 